\title{
EQUITEXTO COMO GÊNERO EMERGENTE NA FORMAÇÃO DE PROFESSORES DE LÍNGUAS
}

\author{
Rosangela Segala de Souza \\ rosangela_s@hotmail.com
}

Tânia Maria Moreira

taniamoreirabr@hotmail.com

\section{RESUMO}

Neste artigo, pretendemos apresentar não só algumas reflexões teóricas sobre formação de professores de línguas, bem como algumas referências relacionadas aos gêneros emergentes, blog e equitexto, que se apresentam como uma contribuição para promover (re)significação de crenças, valores e condutas de professores, em processo de formação continuada.

\section{INTRODUÇÃO}

Segundo Toffler (1995), a sociedade, de modo geral, vem passando por diferentes ondas, tais como a agrícola, a industrial e a do conhecimento e, em cada uma delas, tem exigido transformações radicais que implicam a mudança de culturas, de hábitos na vida do homem. Na era do conhecimento em que estamos vivendo, as tecnologias de informação e comunicação (TIC) vêm forçando mudanças. Não cabe mais, ao professor de línguas, o papel de ensinar o aluno apenas a decodificar sinais lingüísticos para identificar dados, informações antecipadamente previstas pelo professor, ou apenas ditar regras normativas de uso da língua, por exemplo, usando como únicos recursos o quadro e o giz, porque as suas funções se modificaram diante das mudanças sociais, uma vez que hoje as máquinas passam informações em maior quantidade, mais atualizadas e com uma velocidade surpreendente.

Entretanto, o que as TIC não conseguem fazer é transformar os hábitos, as crenças dos homens com a mesma rapidez com que transmitem informações. Compete, então, às instituições educacionais e aos professores assumir essa função. Macedo (1999, p. ix), ao elaborar o prefácio do livro "Ensinar: agir na emergência, decidir na incerteza" de Perrenoud (2001), menciona que "(...) hoje ensinar é agir na emergência e decidir na incerteza, ensinar como resultante disso é igualmente agir com competência". No nosso entendimento, saber agir com competência significa ativar crenças e desejos, tomar decisões e selecionar tanto métodos quanto recursos, bem 
como criar soluções genuínas para resolver problemas. Essas competências, no entanto, demandam não só um professor reflexivo e crítico com uma base de conhecimentos teóricos e procedimentais, como a projeção de cursos de formação de professores voltados, conforme Perrenoud (idem), para a transformação estrutural da profissão.

Segundo um estudo realizado utilizando a ferramenta chat, percebemos que esse gênero, conforme propõe Marcuschi (2004), pode se constituir em um instrumento importante para realizar trocas entre profissionais reflexivos e críticos em um curso de formação de professores que priorize acompanhar possíveis mudanças reflexivas teóricas e práticas dos aprendizes. Mas, para que os professores em atuação se tornem reflexivos e críticos, precisam aprofundar conceitos e desenvolver algumas habilidades em contexto de aprendizagem.

Com relação a conceitos de leitura, gramática e produção textual, percebemos que os professores participantes do referido estudo manifestaram o domínio teórico-prático de concepções tradicionais da cultura de ensinar e aprender línguas e, forte resistência à mudança, fatos que nos levaram a refletir teoricamente e a pensar sobre algumas ações que poderiam contribuir para (re)configurar o quadro detectado. Nesse artigo, portanto, pretendemos apresentar não só algumas reflexões teóricas construídas em função dos resultados obtidos na experiência brevemente relatada, mas também mencionar um caminho viável de ação em que gêneros emergentes, como blog e equitexto, apresentam-se como uma perspectiva de promover o diagnóstico, a tomada de consciência, a reflexão crítica e a (re)significação de crenças, valores e condutas de professores, em processo de formação continuada. Schneuwly (1994, p. 07, apud Liberali, 1999) considera o gênero textual como (mega)instrumento, no sentido vygotskiano do termo, ou seja, como mediador das ações discursivas que acontecem entre sujeitos.

\section{REFLEXÕES TEÓRICAS QUE EMBASAM UMA PROPOSTA DE FORMAÇÃO CONTINUADA DE PROFESSORES}

A fim de que se processe a revisão de crenças disfuncionais e a construção e reconstrução de valores e ações, não só pedagógicas, como também, sociais e políticas, uma proposta de formação de professores requer ações alicerçadas por um 
modelo holístico. Ações que possibilitem o diagnóstico da cultura de ensinar e aprender, que segundo Morin (2001, p. 57), é o conjunto de "crenças, idéias, valores, mitos, que se transmite de geração em geração, se reproduz em cada indivíduo, controla a existência da sociedade e mantém a complexidade psicológica e social" e fornece diretrizes e estratégias de ação de forma cooperativa entre os envolvidos, voltadas para o contexto atual. De acordo com Morin (2000, p. 20), o grande desafio da mudança consiste em "reformar o ensino para que este possa levar à reforma do pensamento e a reforma do pensamento, por sua vez, levar à reforma do ensino".

Nesse sentido, uma proposta de formação continuada crítico-reflexiva deve considerar como relevante as dimensões epistêmica, alética, deôntica e axiológica da rede cognitivo-afetivo-comportamental (Richter, 2004; Richter e Paz, 2004) responsável pelo funcionamento integrado e direcionado da cognição dos indivíduos que desempenham determinados papéis em sua cultura (D’Andrade, 1987).

Segundo Leitch \& Day (2000), as mudanças ocorrem se os aspectos emocionais e os valores do professor forem trabalhados e modificados. Para um trabalho que contemple a mudança da cultura de ensinar e aprender enraízada pelos professores de língua materna, os referidos autores (idem) apontam para a associação da pesquisa-ação com ferramentas conceituais das psicoterapias, como suporte auxiliar. Nesse sentido, os conceitos, pressupostos e técnicas da terapia cognitiva, com adequações para o contexto de formação de professores, auxiliaria no sentido de promover (re) significações de crenças disfuncionais, quebra de resistências e conseqüentemente transformações teórico-práticas dos docentes com relação ao ensino de leitura, gramática e produção textual.

A terapia cognitiva, de acordo com Beck (1997), preocupa-se com o desenvolvimento cognitivo do indivíduo, com o levantamento de disfunções conceituais e em estabelecer relações de confiança, cordialidade, empatia e respeito entre os envolvidos em um trabalho, além de enfatizar a colaboração, a participação em que os envolvidos tenham a iniciativa de tomar decisões. Prioriza o uso de diferentes estratégias cognitivas para mudar simultaneamente pensamento, humor, comportamento, objetivos e a educação do indivíduo para que possa avaliar e responder a seus pensamentos e crenças disfuncionais, enfatizando a prevenção à recaída, tornando-se, assim, autônomo e capaz de gerenciar seu próprio comportamento. 
Conforme o mesmo autor (idem), o modo como as pessoas se sentem está associado ao modo como elas interpretam e pensam sobre uma situação. Estes pensamentos estão ligados a fenômenos cognitivos mais duradouros constituindo as crenças, que podem ser facilmente percebidas em manifestações discursivas e atitudinais. Tais verificações podem se efetuar por intermédio do Paradigma Indiciário que conforme Eco \& Sebeok (1991) sugere a formulação de hipóteses explicativas a partir dos dados fornecidos nos registros ou marcas lingüísticas dessas pessoas, que poderão se confirmar ou não, tendo em vista os demais aspectos da epistemologia pierceana.

Ainda de acordo com o modelo holístico (Richter, 2004), os entendimentos profundos, globais, rígidos e supergeneralizados, tidos pelo sujeito como verdades absolutas que formam as crenças centrais, apresentam conexão com o nível axiológico das representações do indivíduo. No nível deôntico, encontram-se as crenças intermediárias, que consistem em atitudes, regras e suposições, freqüentemente compensatórias e não articuladas, formadas pela influência das crenças. As crenças subjacentes das pessoas influenciam sua percepção, que é expressa por pensamentos automáticos específicos à situação. Esses pensamentos, por sua vez, manifestam-se através das emoções, provocando reações e outras manifestações de conduta (Moreira \& Souza, 2004).

No sentido de diagnosticar e incitar uma mudança de paradigma de ensinoaprendizagem de leitura, gramática e produção textual, uma revisão e superação de disfunções conceituais e possíveis mudanças, apresentam-se como alternativa instrumentos de análise e acompanhamento baseados em gêneros textuais emergentes, originados da necessidade, cada vez maior, de se estabelecer interações que, principalmente, nas tecnologias de informação e comunicação (TIC) se processa via língua escrita.

Segundo Marcuschi (2004), os gêneros textuais emergentes são fenômenos que estão se constituindo como gênero, impostos por situações sociais, históricas e tecnológicas como os ambientes virtuais, espaços que utilizam a escrita eletrônica para a produção e o processamento textual. De acordo com Dolz e Schneuwly (1996, apud Cristóvão, 2002, p. 41), os gêneros textuais "constituem-se como modelos e instrumentos necessários para atividades de escrita e leitura".

No momento em que os gêneros eletrônicos constituem modelos e instrumentos de produção escrita como forma de comunicação e sabemos que nossas práticas 
discursivas e sociais perpassam, conforme Fairclough, (1992), nossa ideologia implícita nas formas de ver, pensar, compreender, recriar ou desafiar e mudar maneiras de falar e agir, ratificamos ser o gênero textual compatível com uma abordagem que permitirá o diagnóstico, o acompanhamento e a análise de referências teórico-práticas dos docentes envolvidos em um curso de formação continuada.

Se os gêneros textuais se constituem de textos, se segundo Bronckart (1999, p.75), "... todo texto se inscreve, necessariamente, em um conjunto de textos ou em um gênero" e, se para Halliday \& Hassan (1989) qualquer texto produzido contém marcas ideacionais, interpessoais e textuais, concluímos que uma análise pormenorizada de produções textuais possibilita o reconhecimento de identidades e atividades sociais pertinentes ao contexto ao qual os autores se inserem.

Portanto, uma proposta de formação continuada de professores de Língua Portuguesa que se disponha a trabalhar com espaços cibernéticos necessita escolher gêneros textuais compatíveis com essa opção, o que nos leva a estudar o blog e o equitexto, na medida em que parecem ser os gêneros textuais emergentes mais apropriados para que concepções sobre ensino de leitura, gramática e produção textual sejam diagnosticadas, acompanhadas e (re)significadas nesse contexto.

\section{BLOG E EQUITEXTO}

O blog, segundo Costa (2004), constitui-se numa "nova cultura, nova forma de publicação on line ... legítima e autêntica da representação de seu autor". Já Ítalo Dutra, doutorando do PGIE, e Rosália Lacerda, ambos pesquisadores da UFRGS (2004), definem os blogs como uma espécie de diário coletivo, um suporte ideal para o desenvolvimento de processos cooperativos com autoria e autonomia. Para a professora especialista em metodologia do ensino e pesquisadora do curso de mestrado em educação da UFRGS, Suzana Gutierrez (2004), ele é um tipo especial de página publicada na internet, extremamente dinâmica e aberta, com poucas subdivisões, com textos curtos, dos quais os mais recentes aparecem no topo da página e apresentam grande quantidade de links para outras páginas. Komesu (2004, p. 111) menciona que "Blog é uma corruptela de weblog e que pode ser traduzido como 'arquivo de rede'". Consideramos o Weblog ou Blog um gênero "emergente", divulgado na Internet, semelhante a uma home page que segue parâmetros comuns 
e, ao mesmo tempo, permite que ele assuma características próprias, dependendo da sua comunidade. Esse gênero pode incorporar na sua estrutura diferentes gêneros textuais e podem ser classificados em individuais e comunitários.

Passeando por alguns endereços, encontramos gêneros do tipo: páginas pessoais, diários de pesquisa, páginas temáticas. Também identificamos projetos educacionais contendo publicação em co-autoria, relato de atividades, documentação eventos, planejamento de desafios cooperativos, resolução de desafios de forma colaborativa recortes jornalísticos, divulgação de pesquisas na forma de notícias de popularização da ciência. Desse modo, podemos dizer que os blogs possibilitam muito mais que expor sentimentos e contar histórias do cotidiano.

Eles podem ser utilizados em cursos de formação continuada de professores de línguas, visando a (re) significação de crenças de leitura, de gramática e de produção textual, na medida em que permitem:

1. Do ponto de vista comunicativo:

- a construção de comunidades que se comunicam, que interagem, que ensinam e aprendem ao mesmo tempo numa intensa troca de informações;

- a manifestação da compreensão que temos de nós, do outro e do mundo;

- a concepção do mundo de diferentes modos;

- o traçado do perfil dinâmico de pessoas a partir de suas interações;

- a divulgação do saber coletivo;

- a percepção mútua das pessoas;

- a divulgação de comentários de possíveis leitores;

2. Do ponto de vista textual:

- a incorporação da polifonia e a intertextualidade,

- o desencadeamento do exercício da expressão artística e hipertextual;

- o desenvolvimento da criatividade;

- o desenvolvimento de habilidades cognitivas como a leitura e escrita;

- o desenvolvimento do imaginário e da fabulação; 
- o desenvolvimento de habilidades de pesquisa - questionamento, registro de hipóteses, de crenças, constatações, de análises e a divulgação da informação e do conhecimento;

- o registro dinâmico do processo de construção do conhecimento; a construção de um trabalho individual ou em equipe de forma livre, autônoma e aberta;

- o retorno à própria produção;

- a reflexão crítica;

- a (re) interpretação de conceitos, de práticas, da realidade.

O equitexto - por nós assim denominado a partir da ferramenta que the dá origem, Equitext - é o produto textual de uma ação cooperativa/colaborativa resultante das reflexões dos participantes de um grupo de estudos. Esse gênero virtual emergente, que possibilita a produção de textos de forma coletiva, que respeita às individualidades, tempos e limites de cada autor, ao mesmo tempo que prioriza princípios éticos-estéticos de reciprocidade, autonomia, autoria e propicia a interação entre os indivíduos, pode ser construído, via web, por meio da utilização de uma ferramenta desenvolvida por um grupo de pesquisadores (alunos e docentes) do Programa de Pós-Graduação em Informática e Educação PPGIE/UFRGS (Alonso et al., 2003), disponível no site: http://equitext.pgie.ufrgs.br/.

Tal instrumento viabiliza o gerenciamento e a edição de mensagens enviadas pelo grupo de autores, de modo síncrono e assíncrono, diferenciando-se de outros meios de comunicação colaborativa on-line (foruns, chats, listas de discussão...), no momento em que as mensagens podem ser inseridas não apenas ao final da lista de contribuições já efetuadas, mas também mescladas a outras já existentes. Podem, também, de comum acordo entre os participantes do grupo, ser modificadas ou excluídas pelos integrantes, mesmo quando não forem de própria autoria.

O Equitext permite visualizarmos a "versão final", ou seja, o texto produzido de forma cooperativa/colaborativa pelos integrantes da equipe, sem a identificação do autor e hora de envio; a "visualização", recurso que registra as contribuições com a identificação do nome de quem enviou e a hora em que o fez; e o "histórico", que apresenta as produções enviadas, mesmo aquelas já excluídas na versão final e na visualização, em ordem cronológica. 
Dessa forma, torna-se possível analisar e refletir sobre a criação coletiva, sua recriação, assim como promover o crescimento conjunto dos membros do grupo. Elícita-se assim a cooperação social, realizada nessa atividade por meio de instrumentos tecnológicos virtuais, representada pelos signos lingüísticos e em conjunto com estudos teórico-práticos, que se apresenta como um caminho para que mudanças da cultura de ensinar e aprender línguas tradicional tornem-se realidade.

\section{CONCLUINDO: UM CAMINHO ON-LINE VIÁVEL NA FORMAÇÃO DE PROFESSORES}

Um curso de formação continuada de professores de línguas que objetiva alterar crenças e condutas, vencendo resistências, necessita determinar uma linha teórica embasadora, capaz de conduzir com segurança uma proposta que envolva de forma ativa e interativa os participantes. De acordo com nossa visão de formação de

professores, a linha teórica sócio-interacionista compreende pressupostos compatíveis com tais objetivos. Além disso, a efetivação de uma proposta requer que abordagens e procedimentos sejam estabelecidos.

Nesse sentido, podemos apontar para a utilização da abordagem de pesquisa-ação e, visto que estamos tratando de um curso on-line, os recursos tecnológicos de comunicação e informação apresentam-se propícios para o desenvolvimento de projetos de leitura, gramática e produção textual. Utilizando os gêneros virtuais emergentes como o blog e o equitexto, torna-se possível a discussão de problemas detectados pelos professores, envolvidos no curso em sua comunidade de origem, assim como a reflexão, o registro a análise e a reavaliação de conclusões, levando à (re) significação de conceitos e práticas.

Portanto, ainda que resistências a mudanças sejam fatores que dificultem alterações teórico-práticas significativas, há caminhos que apontam de forma promissora para que a educação siga a onda das transformações sócio-culturais que devem se refletir em uma nova cultura de ensinar e aprender línguas. 


\section{BIBLIOGRAFIA}

ALLONSO,C. Et al. Software equitext - uma ferramenta para escrita colaborativa na web. 2003, disponível em www.tise.cl/archivos/tise2003/ software/Software

BECK, J. Terapia Cognitiva: teoria e prática. Porto Alegre: Artes Médicas, 1997.

BRONCKART, J. P. Atividade de linguagem, textos e discursos: por um interacionismo sócio-discursivo. Trad. Anna Rachel Machado, Péricles Cunha SP: EDUC, 1999.

COSTA, R. Blogs e Fotologs: a nova "cultura". Acesso em set/2004. Disponível em http://www.pucsp.br/linc/blog/archives/000067.html, publicado em 26/10/2003.

CRISTÓVÃO, V. L. "Modelo didático de gênero como instrumento para formação de professores." In: MEURER, J. L. MOTTA-ROTH, D. (orgs) Gêneros textuais e práticas discursivas: subsídios para o ensino da linguagem. SP: EDUSC, 2002.

D'ANDRADE, R. (1987). "A folk model of mind." In: HOLLAND, D. \& QUINN, Cultural Models in Language \& Thought. Cambridge: Cambridge University Press, 1995. p.112-148.

DUTRA, I; LACERDA, R. Tecnologias na escola: algumas experiências e possibilidades.

URL http://www.cinted.ufrgs.br/renote/fev2003/artigos/italo_tecnologias.pdf.

ECO, U; SEBEOK, T. A. O signo de Três. S. P.: Editora Perspectiva, 1991

FAIRCLOUGH, N. Discourse and social change. Cambridge: Polity Press, 1992.

GUTIERREZ, S. Projeto Zaptlogs: as tecnologias educacionais informatizadas no trabalho de educadores. Acessado em set/2004. Disponível em: http://www.eproinfo.mec.gov.br/upload/ReposProf/Tur80137/img_upload/suzana_guti errez.pdf.

HALLIDAY, M. A. K \& HASSAN, R. Language, context, and text: aspects of language in a social-semiotic perspective. Oxford: Oxford University Press, 1989.

KOMESU, F. C. Blogs e as práticas de escrita sobre si na Internet. In: MARCUSCHI, L. A. e XAVIER, A.C. (org) Hipertexto e_gêneros_digitais. Rio de Janeiro, Editora Lucerna, 2004.

LEITCH, R \& DAY, C. (2000) Action Research and Reflective Practice: towards a holistic view. disponível em http://www.triangle.co.uk/ear/ 
LIBERALLI, F. C. O diário como ferramenta para a reflexão crítica. São Paulo: Pontifícia Universidade Católica, Tese de Doutorado, 1999.

MARCUSCHI, L.A. Gêneros textuais emergentes no contexto da tecnologia digital. In: Hipertexto e gêneros digitais: novas formas de construção de sentido. RJ: Editora Lucerna, 2004.

MOREIRA, T. \& SOUZA, R. "Desenvolvimento continuado de professores de línguas no ciberespaço" In: Linguagens \& cidadania. Disponível em: <www.ufsm.br/linguagem_e_cidadania > Edição 11: Jan./jun 2004

MORIN, E. A cabeça bem-feita: repensar a reforma, reformar o pensamento. Tradução Eloá Jacobina. Rio de Janeiro: Bertrand Brasil, 2000.

Os sete saberes necessários à educação do futuro. 3. ed. SP: Cortez; Brasília, DF : UNESCO, 2001.

PERRENOUD, P. Fomando professores profissionais: quais estratégias? Quais competências? 2 Ed. POA: Artmed, 2001

RICHTER, M.G. "Rumo a uma Concepção Holística de Formação Docente". In: Expressão Vol. 1, № 1, Jan/jun 2004, p.120-124.

RICHTER, M.G.; PAZ, D.M.S. A Horizontalização de Superação das Hierarquias e Diferenças em um Diário de uma Acadêmica em Formação. União da Vitória: II SIGET, 2004. Painel. 